\title{
Capacity Payments and the Pricing of Reliability in Competitive Generation Markets
}

\author{
Angela S. Chuang, IEEE Student Member \\ Dept. of Electrical Engineering and Computer Science \\ University of California, Berkeley \\ Berkeley, CA USA
}

\author{
Felix Wu ${ }^{*}$, IEEE Fellow \\ Center for Electrical Energy Systems \\ University of Hong Kong \\ * On leave from the University of California, Berkeley
}

\begin{abstract}
In restructured electric power industries around the world, power pool designers have enabled generators to earn revenues consisting of energy and capacity payments. This paper discusses uses and abuses of capacity payments, and links provision of these payments to the issue of pricing reliability. A general formula for determining the ideal capacity price in a generation supply system is presented and the theoretical basis discussed. Methods of achieving an ideal level of system reliability through price-setting of capacity payments (in more regulated markets) and through price discovery (in more competitive markets) are contrasted. The paper concludes with market design recommendations that could better realize customer preference for reliability at prices customers are willing to pay.
\end{abstract}

Keywords: Power generation reliability, Power generation economics, Power system reliability, Power system economics, Power generation planning.

\section{Introduction}

In competitive power industries around the world, power pool designers have enabled generators to earn revenue based on energy production and on available capacity. The latter revenue component is called a capacity payment in this paper. Capacity payments have been frequently used to compensate generators for improving reliability. These payments are important revenue sources for generating units that are scheduled to provide available capacity but would more likely not be called to produce electricity. Provisions for capacity payments have also been made out of concern that generators would not recover investment costs when only receiving energy payments from competitive generation markets.

Provisions for capacity payments can be found in various restructured energy and reliability reserve markets around the world. For example, generators have earned capacity payments through participation in the British, Spanish, and PJM (Pennsylvania, New Jersey, Maryland) power pools. Generators also earn capacity payments through participation in reliability reserve markets operated by the California Independent System Operator (CA ISO). Although capacity payments are being offered in different markets that vary by type and geographic region, the idea behind these payments have been consistent in that the payments 1) are based on capacity made available verses energy actually supplied, and 2) provide sources of revenue that by design compensate generators for the value capacity adds to system reliability.

That capacity payments exist at all in many competitive electric power industries indicates that sheer generation capacity provides value even in the absence of generation. The value of uncalled reserve capacity is basically enhanced reliability. Available capacity in a power system adds to system-wide reliability since excess capacity on reserve lowers the probability and impact of an outage event. Actual prices set for these payments directly impact generator behavior in both the short and long run. Long run capital investment decisions in turn influence generation supply reliability (in terms of adequacy [1]). Hence prices offered for capacity in competitive markets ultimately affect resulting system reliability.

Section 2 commences with a look at capacity payment abuses that have surfaced in the British and California electric power industries, respectively. Next, the paper provides a description of capacity payments under ideal conditions. Section 4 presents a framework for assessing ideal capacity payments rates in environments where prices are administratively determined. There, the Value of Service Reliability approach [6] is extended to derive capacity prices that strike an ideal balance between investment costs and reliability. In Section 5, the paper explores purposes of capacity payments and links their provision to the issue of pricing reliability within a system. Achieving an ideal level of system reliability through price-setting (in more regulated markets) and through price discovery (in more competitive markets) are contrasted. The paper concludes with recommendations on market design and pricing schemes that could better realize customer preference for reliability at prices customers are willing to pay. 


\section{Problems Experienced with Capacity Payments}

\subsection{British Experience}

Concerns expressed prior to the onset of the deregulated British system included uncertainties as to whether generating units could recover their investment costs via receiving only energy payments from the energy pool [2]. As a result, a capacity revenue component was devised which was to be paid to all units supplying available capacity in the pool. The capacity element was set up to be partly determined by generation system availability through a loss of load probability (LOLP) measure, and partly determined by regulators through a decree on the value of loss load (VOLL).

In a perfectly competitive environment, arguments for capacity payments to augment energy payments may be well founded. However, excessive market power comprised the actual British generation industry to begin with, and abuses of capacity payments resulted. Generators found early on that capacity payments were particularly sensitive to the amount of spare capacity declared in the pool [3]. The method used to compute LOLP exaggerated the probability that plants would not be available, and led to magnified capacity payments. Before the problematic LOLP computation scheme was revised, generators could mis-report unavailability and collect capacity payments based on an invalid predication of scarce capacity. Even after revision, rules for computing LOLP led to other perverse affects, such as encouraging generators under certain circumstances to delay redeclaring availability after experiencing a fault.

Such problems resulted in magnified capacity payments to generators. During the 1994-95 financial year alone, capacity payments were $20 \%$ of total payments for generation in the British pool [3]. The payments from that one year would have paid for construction of $6 \%$ of total existing capacity. Therefore, the possibility of gaming by generators to influence capacity payments was very significant in the British pool.

\subsection{California Experience}

Unlike the British pool, California auction markets for energy contain no capacity component to compensate generators. Scheduling coordinators like the Power Exchange (PX) only pay generators for scheduled energy. Capacity payments, on the other hand, are awarded by the Independent System Operator (ISO) to units that supply reserves in one of four ancillary service markets. Separate markets exist for regulation, spinning, non-spinning, and replacement reserves, respectively. These auction markets pay scheduled reserves according to market-clearing capacity prices, regardless of whether energy is produced or not from the reserves. So in contrast to the British pool, capacity payments in California are primarily determined through competitive auction mechanisms.

Nevertheless, California markets for reserves have not always functioned competitively [11]. The markets have exhibited extreme price volatility even under long periods of unchanged demand. Prices for lower quality reserves like replacement reserve have at times surpassed that of higher quality reserves such as regulation. Moreover, capacity prices in reserve markets have frequently exceeded energy prices in the Power Exchange. Problems with generator gaming on capacity bids have also been experienced. For example, clearing prices for replacement reserves reached $\$ 9999 / \mathrm{MWh}$, the maximum price bid acceptable by computer software, during certain hours of the first summer of ISO operation. The ISO is rumored to have spent millions for purchasing these reserves, compared to $\$ 1500$ if they had been procured under original utility bid cap rates [12]. At the time of writing, the ISO was imposing a $\$ 250 / \mathrm{MWh}$ price cap on all ancillary services. Clearly, the evidence indicates that capacity reserve markets have not functioned competitively in California.

\section{Capacity Payments Under Ideal Conditions}

Ideal pricing for capacity reserves by definition achieves a balance between economic efficiency and investment incentives [3]. That is, prices must be kept close to costs (if consumers are to benefit from the affects of competition on prices), but not so low as to discourage investment (if reliability is to be maintained over time). Both regulators and designers of competitive markets alike commonly strive to achieve such a balance within both traditional and competitive market settings, respectively.

Competitive and regulated environments differ however in the way prices are determined. In regulated environments, regulators set prices; but in competitive environments, the market does (or at least should). Thus in highly regulated environments, the aim of administrators is to set prices that approximate the ideal situation described above. Likewise in competitive environments, the challenge to market designers is to design market systems and mechanisms so that the market (of buyers and sellers) approximates the ideal on its own. In the next section, how to approximate the ideal is examined within a regulated setting.

\section{Value of Service Reliability}

In this section, the VOS technique is applied towards assessing a price for capacity that achieves an ideal balance between economic efficiency and proper investment incentives (i.e., low costs verses enhanced reliability). 


\subsection{Origins and Theory}

The Value of Service (VOS) reliability technique is a reliability evaluation approach designed by utilities for generation planning purposes [6]. The overall formulation associated with the approach incorporates service costs and customer valuations of reliability worth. By including valuations on reliability worth into the planning formulation, the VOS technique presented utilities with an analytical method for planning generation resource acquisition at levels of reliability commensurate with customers' willingness to pay. At the time the technique was introduced, regulators deemed the tool extremely innovative to the utility planning process. ${ }^{1}$

The VOS technique was originally construed under a centralized planning paradigm. Consequently, responsibility for implementing applications originally cited for the approach typically belonged to the utility. These applications include determination of reliability requirements; analysis of demand-side management programs; analysis of utility-owned supply-side projects; optimal scheduling of maintenance; evaluation of bulk power transactions; and analysis of resource acquisitions issues [6].

In particular, generation planning based on VOS criterion can be used to determine optimal levels of capacity expansion and reliability for both utilities and their customers. By definition, optimal expansion achieves an economic balance between investment costs and reliability. According to the approach, optimality is achieved when capacity acquisition is such that the marginal costs of additional reserves is equal to the marginal benefit of the additions, all evaluated at the margin.

\subsection{Extension}

Although the VOS technique was originally construed under a centralized planning environment, it is applicable to decentralized settings as well. The technique can be used to determine a price for capacity reserves that achieves an ideal balance between investment incentive (or adequate reliability) and economic efficiency (or low electric energy costs) in competitive generation environments. Indeed the authors of the approach had suggested that VOS-based marginal capacity costs be used to calculate non-utility generator payments. As an extension, this paper shows how ideal capacity reserve prices can be computed by reinterpreting marginal costs in the VOS approach as prices. These resultant prices can be used as a basis for determining capacity payment rates in centralized planning environments or other environments in which common rates for capacity payments are set by regulators.

1. comments on pp. 833-834 in [6]

\subsection{Ideal Capacity Reserve Price}

According to the VOS approach, an optimal amount of capacity acquisition occurs when the marginal cost of additional reserves is equal to the marginal benefit of all additions. Analytically, the marginal benefit of a resource addition in the amount of $X_{o}$ MWe may be expressed as

$$
\left|\frac{d}{d X_{o}}\left[R\left(X_{o}\right) \cdot q\left(X_{o}\right)\right]\right|,
$$

where $X_{o}$ is the total amount of additional capacity resource acquired; $R\left(X_{o}\right)$ is a reliability assessment on the generation system resulting from additional capacity procurement; and $q\left(X_{o}\right)$ represents customer outage costs in $\$ / \mathrm{MWh}$ as a function of additional resource acquisition.

One may interpret the VOS optimality criterion on service costs in a centralized setting to be a criterion on prices offered for capacity reserves in a decentralized setting ${ }^{2}$. Using this approach, price offered for capacity reserves would equal the marginal benefit of capacity reserve additions acquired during the time period under consideration. Thus according to the VOS criterion, the ideal price for capacity payments is given by

$$
\mathrm{P}\left(X_{o}\right)=\left|\frac{d}{d X_{o}}\left[R\left(X_{o}\right) \cdot q\left(X_{o}\right)\right]\right| .
$$

Furthermore, the capacity reservation revenue of a generator supplying $x_{o i}$ MWe is the product of the resultant price and the quantity of reserves supplied by the generator. Explicitly, the revenue for a generating unit supplying $x_{o i}$ MWe of capacity out of an industry total of $X_{o}$ MWe is $\mathrm{P}\left(X_{o}\right) \cdot x_{o i}$.

\subsection{Computation}

In order to compute the ideal capacity reserve price, a reliability measure must be selected for use in the price computation formula. Common measures on generation supply adequacy include loss of load expectation ( $L O L E)$ and expected unserved energy (EUE). EUE is the chosen reliability measure in our example.

By substituting $R\left(X_{o}\right)$ in Equation (2) with $E U E\left(X_{o}\right)$ and expanding the derivative of the product we obtain a formula by which the ideal capacity price can be computed from expected unserved energy:

$$
\begin{aligned}
& \left|\frac{d}{d X_{o}}\left[\operatorname{EUE}\left(X_{o}\right) \cdot q\left(X_{o}\right)\right]\right|= \\
& \quad\left|q\left(X_{o}\right) \cdot \frac{d}{d X_{o}} \operatorname{EUE}\left(X_{o}\right)+\operatorname{EUE}\left(X_{o}\right) \cdot \frac{d}{d X_{o}} q\left(X_{o}\right)\right|
\end{aligned}
$$

2. Under perfect competition, prices equal costs. 
where $q\left(X_{o}\right)$ is system-average customer outage cost and $\operatorname{EUE}\left(X_{o}\right)$ is expected unserved energy after additional capacity procurement. EUE can be computed as part of the area under the equivalent load duration curve resulting from a particular convolution operation (See p. 171 in [7]). In our application, EUE is computed as:

$$
\begin{aligned}
& \operatorname{EUE}\left(X_{o}\right)= \\
& C_{0}+L_{\text {peak }}+X_{0} \\
& T \cdot \int\left((1-p) \cdot \operatorname{ELDC}_{0}(x)+p \cdot \operatorname{ELDC}_{0}\left(x-X_{0}\right)\right) d x \\
& \quad C_{0}+X_{0}
\end{aligned}
$$

where $C_{\mathrm{o}}$ is total initial capacity; $L_{\text {peak }}$ is peak system load; $E L D C_{0}$ is the final equivalent load duration curve of the initial system; $T$ is the duration of the time period under consideration; and $p$ is the forced outage rating assumed on additional capacity procurement.

Substituting the above expression for $\operatorname{EUE}\left(X_{o}\right)$ into Equation (3) and taking the derivative, we arrive at the following formula for computing ideal capacity price:

$$
\begin{aligned}
\mathrm{P}\left(X_{o}\right)=T \cdot(1-p) \cdot E L D C_{0}\left(C_{0}+X_{o}\right) \cdot q\left(X_{o}\right) \\
+\operatorname{EUE}\left(X_{o}\right) \cdot \frac{d}{d X_{o}} q\left(X_{o}\right) .
\end{aligned}
$$

Assuming constant outage costs, the ideal capacity price becomes

$$
\mathrm{P}\left(X_{o}\right)=T \cdot(1-p) \cdot E L D C_{0}\left(C_{0}+X_{o}\right) \cdot q,
$$

where $C_{0}, E L D C_{0}, T$, and $p$ are as previously defined. A detailed derivation of the first component of Equation (5) is contained in the Appendix.

Generally, customer outage costs vary according to total capacity acquisition. That is, in general $q$ is a function of $X_{o}$. However, assuming a constant rate on outage costs can greatly simplify computation of capacity price. If we apply this assumption, the latter pricing formula (6) can be regarded as an approximation to (5).

Comparing the generalized and simplified pricing formulas, we note differences in computational requirements. Since Equation (5) essentially contains the entire expression in Equation (6) plus an added term, the latter is more simplistic to evaluate. Computation of (6) merely involves evaluating the function $E L D C_{0}$ at one value and computing a product. On the other hand, (5) has additional computational requirements which are mainly embodied in the extra term:

$$
\operatorname{EUE}\left(X_{o}\right) \cdot \frac{d}{d X_{o}} q\left(X_{o}\right)
$$

Evaluating this term requires calculating EUE (i.e., performing a convolution and integral operation), plus computing a derivative and a product. In contrast, Equation (6) does not necessitate computation of EUE nor any derivatives and integrals. Therefore, utilizing the simplified formula can significantly speed up computation of ideal capacity price.

A trade-off for gains in speed, however, is a loss in accuracy stemming from the constant outage cost assumption. In general, the flatter the marginal outage cost curve is at the margin, the more negligible is the loss in accuracy.

\subsection{Numerical Example}

In Figure 1, a sample price curve for capacity reserves is plotted as a function of total reserve acquisition. The curve corresponds to the test system with parameters given in Tables 1 and 2 for the case of constant average customer outage costs. The test system was partially adapted from $[5]$.

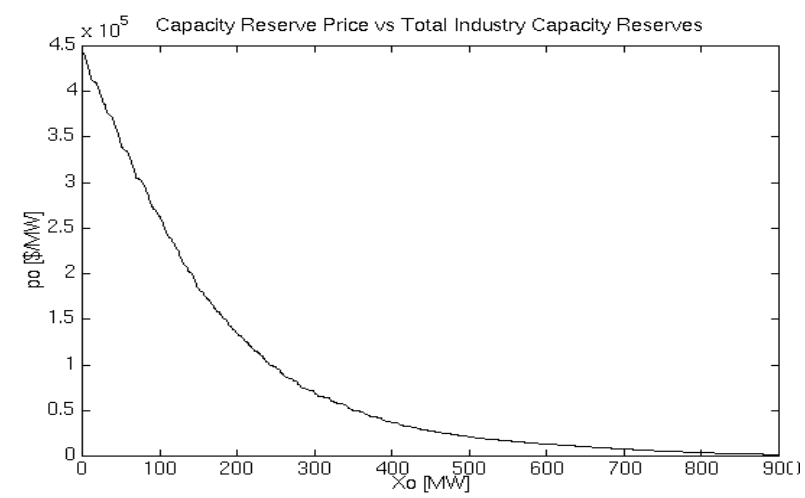

Fig. 1 Price Curve for Capacity Reserves

Table 1: Generating Units of Test System

\begin{tabular}{|l|l|l|l|l|}
\hline $\begin{array}{c}\text { No. } \\
\text { of } \\
\text { units }\end{array}$ & Technology & $\begin{array}{c}\text { Size } \\
(\mathrm{MWe})\end{array}$ & $\begin{array}{c}\text { Operating } \\
\text { Cost } \\
(\$ / \mathrm{MWh})\end{array}$ & $\begin{array}{l}\text { Forced } \\
\text { Outage } \\
\text { Rate }\end{array}$ \\
\hline 1 & nuclear & 650 & 4 & .05 \\
\hline 1 & coal & 650 & 10 & .04 \\
\hline 1 & oil & 350 & 20 & .02 \\
\hline 2 & oil & 300 & 30 & .02 \\
\hline 1 & gas turbine & 200 & 50 & .01 \\
\hline
\end{tabular}

Table 2: Test System Parameters

\begin{tabular}{|r|c|}
\hline Total initial capacity $C_{\mathrm{o}}$ & $2450 \mathrm{MWe}$ \\
\hline Initial load duration curve & IEEE Reliability Test System [10] \\
\hline Duration of time period $T$ & $1 \mathrm{yr}$ \\
\hline Avg forced outage rate $p$ & 0.02 \\
\hline Avg customer outage cost $q$ & $\$ 3 / \mathrm{Kwh}$ \\
\hline
\end{tabular}




\subsection{Comparison with British Pool's Capacity Element}

The proposed method for pricing capacity can shed some analytical light on the scheme used in the British pool ${ }^{3}$ to compensate generators for available capacity. Very interestingly, there are close similarities between Equation (6) and the formula that had been in use in the British power pool to compute capacity payments. The capacity element of the British pool purchase price is

$$
L O L P \cdot(V O L L-S M P) .
$$

where $L O L P$ is the loss of load probability at a given time; VOLL is the value of loss load (an administratively decreed value); and $S M P$ is the system marginal price of the pool at the time [8].

Comparing expression (7) against the formula derived in Equation (6), we note similarities between terms. In Equation (6), $E L D C_{0}\left(C_{0}+X_{o}\right)$ is actually a loss of load probability; namely, that of the generation supply system after all capacity additions secured during the period in question are considered. Similarly, the LOLP factor in expression (7) is based on the capacity availability situation of the pool at the time. Thus the meaning of the $E L D C_{0}\left(C_{0}+X_{o}\right)$ factor of the first equation is equivalent to the meaning of the $L O L P$ factor of the British expression.

Similarly, VOLL-SMP in expression (7) closely resembles $q$ from the VOS-derived formula. VOLL is considered to be the maximum cost an average customer would be willing to pay to avoid a service interruption [8]. Likewise $q$ in Equation (6) is a valuation on reliability worth measured in terms of customer outage costs. So both factors, $V O L L-S M P$ and $q$, take into account costs associated with loss of load events, and hence are related. The British factor deducts $S M P$ from VOLL to account for the fact that all generating units that declare available capacity will receive capacity payments on top of any energy payments won in the British pool - the energy payments being based on the SMP.

There are two factors, $T$ and 1- $p$, remaining in Equation (6) that do not appear in expression (7). These two elements serve to yield a more general formula for computing capacity prices, by taking into account a general time period and a reliability measure on capacity reserve acquisitions. $T$, a time duration, converts energy into capacity units; whereas $p$, an average forced outage rating on reserve acquisitions, is unit-less. If the $S M P$ is based on hourly dynamics, then the implicit time duration in the British expression would be one hour. However, lack of a

3. The British pool has since dissolved. Thus, the pricing method described in this subsection is no longer in use. forced outage measure in the British expression indicates an assumption of perfect availability on all declared capacity.

In summary, the LOLP/VOLL scheme once utilized by the British system for computing capacity prices contains similar components to Equation (6). Both techniques for computing capacity prices factor in a reliability measure and an estimate on reliability worth for the generation system in question. However, whereas prices for capacity were administratively decreed in the British system (thereby necessitating blind acceptance from participating generators), the VOS-based method is theoretically based and provides a framework for determining ideal capacity payment rates. VOS methodology also provides an analytical method of assessing whether a proposed pricing scheme approximates an ideal cost and reliability balance within a system.

\subsection{Limitations of Approach}

Although the VOS technique provides a sound theoretical basis by which ideal rates for capacity payments may be computed, the method is also limited in applicability.

The method assumes a regulatory price-setting environment for setting capacity payment rates. Therefore, the proposed method is applicable to only those systems in which capacity prices are administratively determined, such as the British pool. The technique can not be applied in markets like the CA ISO-operated reserve markets in which prices are determined via auctions.

Futhermore, full power of the VOS approach to address individual customer preferences has not yet been realized. The formula derived in Section 4.4 is based on the use of system-wide averages for 1) customer outage costs and 2) forced outage rates of capacity resource additions. Therefore, within the basic VOS model all customers pay for and receive the same level of system reliability. Consequently, the proposed pricing scheme induces capacity resource acquisitions at levels that optimize for the average customer.

\subsection{Reliability Worth Assessment Requirement}

Like the British capacity element, the proposed method of determining ideal capacity prices depends on access to reliability worth information. Data on worth directly factors into capacity price through the outage cost term $q$. So application of VOS-based capacity prices presumes fairly accurate estimations on reliability worth.

Various ways of determining reliability worth exist across electric power industries. Traditionally, utilities conducted customer surveys to evaluate reliability worth by estimating customer outage costs. [6] mentions several ways of 
measuring customer outage costs. They include: proxy methods that indirectly measure outage costs; marketbased methods that examine actual customer behavior in response to service options; after-the-fact measurement methods that quantify impacts of actual outages; and survey methods which tabulate customer responses to hypothetical outage scenarios. There are also other engineering and market-based methods for establishing a value on reliability worth. In particular, [8] details a proposal for evaluating VOLL that relies on customer surveys, and [9] describes a methodology that also relies on customer surveys for electric service reliability worth evaluation. Reliability worth may also be reflected through payment terms contained in long term contracts held by reliability mustrun generating units (like those contracted with the ISO).

Regardless of the method of estimation, it should be understood that any reliability worth evaluation technique offers merely an estimate on the value of reliability within a particular service area. Also, since valuation on reliability worth is system dependent, any data used in estimations should originate from the particular service area in question. Furthermore, because actual outage costs, VOLL, and other measures of reliability worth depend on many factors including geography, weather, outage duration, cause of outage, etc., evaluation of reliability worth can be a nontrivial requirement.

\subsection{Difficulties of Applying in Practice}

The complexity of assessing reliability worth is one source of difficulty in administratively determining ideal capacity prices. Another source of difficulty involves assessing a value on system reliability itself. From Equation (6), the reader will note that VOS-prescribed capacity prices, like British capacity prices, are dependent on the respective values of reliability worth and system reliability used in the analyses. However, the time-varying nature of system reliability can lead to complications in making accurate estimates. The difficulties involved in assessing system reliability will be expanded on next.

Generation system reliability may be expressed in terms of loss of load probability, or other established reliability measures like expected unserved energy (EUE) and loss of load expectation (LOLE). Regardless of the measure chosen, reliability is directly affected by capacity availability amongst all generating units in a particular system at a given time.

Because of the time-varying nature of available capacity, complications can arise from performing apriori reliability assessments. For example, in the British pool LOLP is the chosen reliability measure that capacity prices are based on. To establish price certainty, LOLP values are computed apriori and based on availability declarations of gen- erating units participating in the pool. However, computing LOLP apriori led to gaming in the British pool early on, as generators sought to improve on capacity payments. As already discussed, mis-reporting availability led to abuses of capacity payment provisions and non-ideal results.

Generally, price-setting schemes that utilize measures of reliability to compute compensation terms will encounter difficulties in practice. The underlying problem is that information reported apriori to assess reliability may not necessarily reflect actual outcomes. This problem is augmented by the possibility of gaming among generators that have an incentive to mis-report information. Nevertheless, the need to establish price certainty for capacity payments necessitates making apriori estimates on system reliability. In conclusion, the difficulty of accurately assessing system reliability is another problem associated with setting capacity payment rates administratively.

\section{Capacity Payments for Pricing Reliability}

\subsection{Uses of Capacity Payments}

Capacity payments have been discussed as common mechanisms in various pools for compensating generators recognized to serve a reliability purpose. Why else have these payments become prevalent in competitive generation markets, and what other purpose can they serve?

Provision of capacity payments serve to hedge risks inherent in energy production and plant investment by providing valuable price signals and incentives [3]. A generator may for example estimate likely capacity payments ahead of time and predict whether a unit will cover its costs from participating in an auction and receiving the capacity price. Furthermore, a history of high capacity prices will act as incentives for additional generation investment and participation in capacity reserve markets. By providing these signals and incentives, capacity prices in turn shape system reliability. High anticipated prices should induce more supply offerings and thus reinforce reliability.

In addition, capacity prices established through price discovery in competitive auctions can address a key question inherent in traditional power industries; namely, the question of what reliability is worth to individual customers. A consumer's willingness to pay a certain price for capacity reserves directly reveals how much the consumer values reliability. Likewise, clearing prices in auctions for capacity reserves can indicate how reliability is valued by an aggregated market of consumers and suppliers, respectively. In such ways, capacity prices can signal the worth of reliability in a system.

Because they signal the worth of reliability as well as influence resulting system reliability, capacity prices for 
reserves are related to the price of reliability. Given necessary technological innovations and market design mechanisms are in place, capacity prices can serve to efficiently price reliability as well as accurately reveal what reliability is worth in a system. More discussion on realizing this possibility is given below.

\subsection{Price-Setting Verses Price Discovery}

Market designers in power industries undergoing restructuring face a choice between instilling mechanisms that rely on price-setting by regulatory entities or implementing competitive market mechanisms that enable price discovery. As discussed in Section 4.9, environments of the former are prone to gaming on reported information. In light of this characteristic plus the general difficulty of estimating values for reliability and reliability worth, price-setting appears an inferior mechanism to price discovery. Rather, price discovery mechanisms could more accurately reveal what reliability is worth to an industry. The information in turn is needed to induce a better balance between economic efficiency and reliability in competitive generation markets.

\subsection{Market Design Recommendation}

The ability to discover what reliability is worth through capacity reserve markets is an advantage of market designs that enable price discovery over those that rely on regulatory price-setting. For capacity prices to directly reveal reliability worth in competitive markets, necessary technological and market mechanisms need to be in place. Consumers would need a way to individually express their preference for service reliability in a way that influences actual demand. This ability could be realized by widely allowing consumers to bid into capacity reserve auctions, within which they can express their preference for reliability at prices they are willing to pay. Moreover, consumers should not be shielded from costs paid for procuring service reliability. The prices that consumers see and directly pay should include service reliability costs, if demand for reserves is expected to be responsive to the costs of procuring them.

Demand-side bidding gives consumers an audible voice regarding their preferences for electricity at whatever level of service desired. For example, demand-side bidding for reserves would enable consumers to reveal how they individually assess the importance of not having their electricity curtailed, and at what prices they are willing to experience a degradation in continuity of service.

California and other regional systems have yet to widely implement such provisions for demand-side bidding in auctions for reserves. For example, in the California system the demand curve [4] for reserves is very inelastic; resembling a vertical line that intersects the aggregate supply curve of units bidding reserves. The inelasticity can lead to a situation of quantity demanded that exceeds total supply bid into auction, as has been experienced in California's reserve markets [11]. Introduction of more elasticity to the demand curve for reserves would ameliorate this problem, by allowing capacity payments to better reflect customer valuation on service reliability. So the facilitation of wide consumer participation in double-sided auctions for reserves could help mitigate the problems experienced in California ancillary service reserve markets.

\section{Conclusion}

The value of uncalled capacity in essence is enhanced reliability. Capacity reserves serve to reduce the probability of loss of load events as well as lessen the impacts of outages. Provisions of capacity payments and attempts to carefully design these payments have been linked in the discussions to the issue of pricing reliability.

In traditional utility environments in which centralized investment planning is conducted, planners may utilize the Value of Service Reliability method detailed in this paper. The VOS technique provides a theoretical basis by which optimal capacity prices can be determined. The technique was used to explain how ideal capacity prices might be determined in environments where they can be administratively set. However, there are difficulties in utilizing the VOS technique in practice, due to requirements on estimating values for reliability and reliability worth that are needed in the analyses.

In more competitive environments, a choice is offered between price discovery and price-setting mechanisms for determining capacity payment rates. The former, price discovery, could better reveal what reliability is worth to an industry, and in turn help induce a greater balance between economic efficiency and reliability in a system. However, to better discover the value of reliability through competitive markets, facilitation of double-sided reserve auctions and other mechanisms that promote consumer responsiveness to prices is recommended.

\section{Acknowledgments}

The authors wish to thank Professor Pravin Varaiya of the University of California at Berkeley for his insightful comments and for his assistance in proof-reading this paper. The research was funded by a Robert M. Noyce Foundation graduate fellowship, and also supported by ARO/ EPRI contract WO8333-04.

\section{References}

1. Billinton, Roy and Allan, Ronald N., Reliability Evaluation of Power Systems, Boston: Pitman Advanced Publishing Program, 1984. 
2. Green, Richard J. and Newbery, David M., "Competition in the British Electricity Spot Market", Journal of Political Economy, Vol. 100, No. 5, 1992.

3. Newbery, David M., "Power Markets and Market Power", The Energy Journal, Vol. 16, No.3, 1995.

4. Carlton, Dennis W. and Perloff, Jeffrey M., Modern Industrial Organization, 2nd Edition, NY: Harper Collins, 1994.

5. He, Y.Q., David, A.K., "Advances in Global Optimization for Generation Expansion Planning", IEE Proceedings on Generation, Trans., and Distribution, Vol. 142, No. 4, July 1995.

6. Burns, Sandra and Gross, George, "Value of Service Reliability”, IEEE Transactions on Power Systems, Vol. 5, No. 3, August 1990, pp. 825-834.

7. Wang, X. and McDonald, J.R., Modern Power System Planning, London: McGraw-Hill Book Company, 1994.

8. Kariuki, K.K. and Allan, R.N., "Evaluation of Reliability Worth and Value of Lost Load", IEE Proceedings on Generation, Transmission, and Distribution, Vol. 143, No. 2, March 1996, pp. 171-180.

9. Gates, J., Billinton, R., and Wacker, G., "Electric Service Reliability Worth Evaluation for Government, Institutions, and Office Buildings", IEEE Transactions on Power Systems, Vol. 14, No. 1, February 1999, pp. 43-50.

10. Reliability Test System Task Force, "IEEE Reliability Test System", IEEE Transactions on Power Apparatus and Systems, Vol. PAS-98, No.6, Nov/Dec 1979.

11. Wolak, F., Nordhaus, R., and Shapiro, C., "Preliminary Report On the Operation of the Ancillary Services Markets of the California Independent System Operator", Market Sur- veillance Committee of the California ISO, http:// www.caiso.com/pubinfo/FERC/filings, August 19, 1998.

12. Brien, Laura, "Why the Ancillary Services Markets in California Don't Work and What to Do about It", paper presented at the POWER Fourth Annual Research Conference on Electricity Industry Restructuring, Feb 1999.

13. Green, Richard, "Draining the Pool: The Reform of Electricity Trading in England and Wales", paper presented at the POWER Fourth Annual Research Conference on Electricity Industry Restructuring, Feb 1999.

\section{Bibliography}

Angela Chuang received her B.S. and M.S. degrees in Electrical Engineering and Computer Science in 1992 and 1995, respectively. Both degrees were received from the University of California at Berkeley. Ms. Chuang also completed a Management of Technology certificate in 1998 under the Haas School of Business and College of Engineering at Berkeley. She is currently a Ph.D. candidate in Electrical Engineering at the same institution. Her research interests include power systems planning, optimization, and game theory.

Felix Wu received his Ph.D. from UC Berkeley, where he is currently a professor of Electrical Engineering and Computer Science, on leave at the University of Hong Kong. Dr. Wu is a Fellow of IEEE.

\section{Appendix}

The first component in the general formula for determining ideal capacity price is derived as follows.

$$
\begin{aligned}
& \left|q\left(X_{o}\right) \cdot \frac{d}{d X_{o}} E U E\left(X_{o}\right)\right|=\left|q\left(X_{o}\right) \cdot \frac{d}{d X_{o}}\left(T \cdot \int_{C_{0}+X_{o}}^{C_{0}+L_{\text {peak }}+X_{o}}\left((1-p) \cdot E L D C_{0}(x)+p \cdot E L D C_{0}\left(x-X_{o}\right)\right) d x\right)\right| \\
& =\left|q\left(X_{o}\right) \cdot \frac{d}{d X_{o}}\left(T \cdot \int_{C_{0}+X_{o}}^{C_{0}+L_{\text {peak }}+X_{o}}(1-p) \cdot E L D C_{0}(x) d x\right)+q\left(X_{o}\right) \cdot \frac{d}{d X_{o}}\left(\begin{array}{c}
C_{0}+L_{p e a k}+X_{o} \\
T \cdot \int_{C_{0}+X_{o}} p \cdot E L D C_{0}\left(x-X_{o}\right) d x
\end{array}\right)\right| \\
& =\left|q\left(X_{o}\right) \cdot \frac{d}{d X_{o}}\left(T \cdot \int_{C_{0}+X_{o}}^{C_{0}+L_{\text {peak }}+X_{o}}(1-p) \cdot E L D C_{0}(x) d x\right)+q\left(X_{o}\right) \cdot \frac{d}{d X_{o}}\left(\begin{array}{l}
C_{0}+L_{p e a k} \\
T \cdot \int_{C_{0}} p \cdot E L D C_{0}\left(x^{\prime}\right) d x^{\prime}
\end{array}\right)\right| \\
& =\left|q\left(X_{o}\right) \cdot \frac{d}{d X_{o}}\left(T \cdot \int_{\alpha}^{C_{0}+L_{\text {peak }}+X_{o}}(1-p) \cdot E L D C_{0}(x) d x\right)+q\left(X_{o}\right) \cdot \frac{d}{d X_{o}}\left(T \cdot \int_{C_{0}+X_{o}}^{\alpha}(1-p) \cdot E L D C_{0}(x) d x\right)\right| \\
& =\left|T \cdot(1-p) \cdot E L D C_{0}\left(C_{0}+L_{p e a k}+X_{o}\right) \cdot q\left(X_{o}\right)-T \cdot(1-p) \cdot E L D C_{0}\left(C_{0}+X_{o}\right) \cdot q\left(X_{o}\right)\right| \\
& =T \cdot(1-p) \cdot E L D C_{0}\left(C_{0}+X_{o}\right) \cdot q\left(X_{o}\right)
\end{aligned}
$$

